\title{
Downregulation of caveolin-1 increases the sensitivity of drug-resistant colorectal cancer HCT116 cells to 5-fluorouracil
}

\author{
ZHAOYANG LI $^{1 *}$, NING WANG $^{2 *}$, CHANGXIN HUANG $^{1}$, YANHONG BAO $^{3}$, YIQIAN JIANG $^{4}$ and GUITING ZHU ${ }^{1}$ \\ Departments of ${ }^{1}$ Oncology and ${ }^{2}$ Ultrasound, Affiliated Hospital of Hangzhou Normal University, Hangzhou, \\ Zhejiang 310015; ${ }^{3}$ Second Clinical College of Zhejiang Chinese Medical University, Hangzhou, Zhejiang 310053; \\ ${ }^{4}$ Department of Radiation Oncology, The First People's Hospital of Xiaoshan, Hangzhou, Zhejiang 311200, P.R. China
}

Received November 4, 2015; Accepted September 14, 2016

DOI: $10.3892 / \mathrm{ol} .2016 .5390$

\begin{abstract}
Colorectal cancer is the third most common type of cancer in men and women. Chemotherapy is an important treatment strategy for patients with terminal stage cancer. However, the development of drug resistance hampers the effectiveness of chemotherapy. Therefore, an effective therapeutic approach to target chemoresistance-associated cellular molecules is required. In the present study, drug-resistant human colorectal cancer HCT116 cells were developed by treating HCT116 cells with increasing concentrations of 5-fluorouracil (5-FU). The present study indicated that the drug-resistance cells (DRC) were resistant to 5-FU compared with parental HCT116 cells by detecting cell survival using an MTT assay. Additionally, the expression of the chemoresistance-associated protein caveolin-1 (Cav-1) was assessed by reverse transcription-quantitative polymerase chain reaction and western blotting. The results revealed that the Cav-1 expression level was significantly higher in DRC compared with that in the parental HCT116 cells. Next, Cav-1 was silenced by small interfering RNA (siRNA) or was inhibited with its specific inhibitor methyl $\beta$-cyclodextrin (MCD). MTT assay demonstrated that Cav-1 siRNA and MCD resensitized DRC to 5-FU. These data reveal that Cav-1 was involved in the development of resistance, suggesting that Cav-1 is a potential target for the treatment of colorectal cancer chemoresistance. In addition, 5-FU combined with Cav-1 siRNA or its specific inhibitor may increase the effectiveness of the treatment strategy.
\end{abstract}

Correspondence to: Dr Changxin Huang, Department of Oncology, Affiliated Hospital of Hangzhou Normal University, 126 Wenzhou Road, Hangzhou, Zhejiang 310015, P.R. China

E-mail: changxhuang@sina.com

${ }^{*}$ Contributed equally

Key words: caveolin-1, drug resistant, colorectal cancer, fluorouracil, survival

\section{Introduction}

Colorectal cancer, also termed colon cancer or rectal cancer, results from abnormal multiplication of cells in the colon or rectum that are able to spread to other parts of the body (1). Statistics indicated that 136,830 new patients with colorectal cancer and 50,310 mortalities from colorectal cancer occurred in the USA in 2014 (2). In China, colorectal cancer is also one of the most widespread malignant tumors, and its incidence is increasing (3). Chemotherapy is widely used in colorectal cancer treatment. However, cancer cells usually show resistance to the drugs, which is the main cause of treatment failure (4-7). Overcoming drug resistance will be significant to improve prognosis and survival. 5-Fluorouracil (5-FU), an anti-cancer drug, is used as one of the standard chemotherapy regimens for colorectal cancer treatment (8). 5-FU acts as an antimetabolite that irreversibly inhibits thymidylate synthase enzyme, resulting in defective synthesis of DNA and RNA, and thus induces apoptosis and inhibits cell growth (9). However, it has been reported that the therapeutic effectiveness of 5-FU is often limited due to the development of drug resistance and toxicity at high doses (10). Thus, an effective treatment strategy is required to repress resistance to 5-FU and resensitize cancer cells to the drug.

Caveolins are a family of membrane-associated proteins that have three members in vertebrates: Caveolin-1 (Cav-1), caveolin-2 (Cav-2) and caveolin-3 (Cav-3), which are the main components of cholesterol-enriched invaginations of the plasma membrane termed caveola membranes (11). Caveola membranes are pivotally involved in receptor-independent endocytosis (11-13), caveolae biogenesis, signal transduction and cholesterol homeostasis (14-16). The cell plasma membrane is the main entry point for chemotherapeutic agents, and membrane-associated proteins are speculated to be involved in the development of resistance, though this phenomenon may be attributed to multiple mechanisms (17). Cav-1, as the principal component of caveolae, plays an important role in material transportation, endothelial infiltration and tumorigenesis (18). Cav-1 acts as a scaffolding protein by interacting with signaling molecules through a caveolin scaffolding domain to modulate gene expression, signal transduction and protein translocation in the cell membrane (18). It is highlighted that Cav-1 plays a crucial role in tumor progression, cell growth, 
invasion and metastasis (19-22). Additionally, it has been shown that Cav-1 is closely associated with the development of drug resistance (23-25).

In the present study, drug-resistant colorectal cancer HCT116 cells were cultivated, and the expression of Cav-1 in these drug-resistant cells (DRC) was explored. Using theCav-1 specific inhibitor methyl $\beta$-cyclodextrin (MCD) and its small interfering RNA (siRNA), the present study determined that Cav-1 was involved in the development of resistance of colorectal cancer HCT116 cells to 5-FU. The current study suggested that targeting the chemoresistance-associated protein Cav-1 may improve the efficiency of chemotherapy with 5-FU.

\section{Materials and methods}

Cell culture. The human colorectal cancer HCT116 cell line (American Type Culture Collection, Manassas, VA, USA) was cultured at the Department of Oncology, Affiliated Hospital of Hangzhou Normal University (Hangzhou, China). Cells were maintained in RPMI-1640 medium (Gibco; Thermo Fisher Scientific, Inc., Waltham, MA, USA) supplemented with $10 \%$ heat-inactivated fetal bovine serum (Gibco; Thermo Fisher Scientific, Inc.), $100 \mathrm{U} / \mathrm{ml}$ of penicillin and $100 \mu \mathrm{g} / \mathrm{ml}$ of streptomycin in a $37^{\circ} \mathrm{C}$ incubator with a humidified atmosphere containing $5 \%(\mathrm{v} / \mathrm{v}) \mathrm{CO}_{2}$.

Development of 5-FU-resistant HCT116 cells. To obtain DRC, human colorectal cancer HCT116 cells were exposed to increasing concentrations of 5-FU ranging from 5 to $40 \mathrm{mg} / \mathrm{l}$ in complete medium. Briefly, HCT116 cells were cultured in $60-\mathrm{mm}$ culture plates for $24 \mathrm{~h}$, and $5 \mathrm{mg} / \mathrm{l}$ of $5-\mathrm{FU}$ was added in the medium for another $48 \mathrm{~h}$. The medium was then replaced with drug-free fresh medium to incubate the cells until $90 \%$ confluence was reached. Subsequently, the cells were trypsizined, re-plated and re-exposed to a double dose of drug. This process was repeated until cells exhibited resistance to $40 \mathrm{mg} / \mathrm{l}$ of 5-FU. Subsequent to exposure to increasing concentrations of 5 -FU for $\geq 3$ months, living cells were collected and termed DRC, which were used for additional experiments.

Cell survival assay. Cell survival was evaluated by MTT assay. Briefly, $1 \times 10^{4}$ cells were seeded in a 96 -well plate and incubated at $37^{\circ} \mathrm{C}$ until $80 \%$ confluence was reached. The cells were then treated with $40 \mathrm{mg} / 1$ of 5 -FU for $0,24,48$ and $72 \mathrm{~h}$, followed by incubation with $20 \mu \mathrm{l}$ of $5 \mathrm{mg} / \mathrm{ml}$ MTT (Sigma-Aldrich; Merck Millipore, Darmstadt, Germany) for additional $4 \mathrm{~h}$. Finally, $200 \mu \mathrm{l}$ of dimethyl sulfoxide was added to lyse the cells, and the absorbance was determined using an ELISA reader (Tecan Austria GmbH, Grödig, Austria) at $570 \mathrm{~nm}$.

Morphological observation of 5-FU-resistant cells. HCT116 cells and DRC were cultured in 60-mm culture dishes for $24 \mathrm{~h}$, and then treated with or without $40 \mathrm{mg} / \mathrm{l}$ of $5-\mathrm{FU}$ for $72 \mathrm{~h}$. Next, the medium was removed and the cells were washed once with RPMI-1640 medium. Cell morphology was observed and images were captured using a vertical microscope (Olympus Corporation, Tokyo, Japan).
Reverse transcription-quantitative polymerase chain reaction $(R T-q P C R)$. Total RNA was extracted from cells using the Total RNA Isolation kit (A\&A Biotechnology, Gdynia, Poland) following the manufacturer's protocol. Complementary DNA was obtained by RT of RNA using the PrimeScript II First Strand cDNA Synthesis kit (Takara Biotechnology, Co., Ltd., Dalian, China) and amplified using TaqMan ${ }^{\circledR}$ Gene Expression Assay (Applied Biosystems; Thermo Fisher Scientific, Inc.) with fluorogenic fluorescein amidite-labeled probes. The primers for Cav-1 and the internal control GAPDH were obtained from Takara Biotechnology, Co., Ltd. The sequences of the primers were as follows: 5'-CTCGAGATGTCTGGG GGCAAATACG-3' (forward) and 5'-GAATTCTATCTC TTTCTGCGTGCTG-3' (reverse) for Cav-1; and 5'-GGCCGT GAAGTCGTCAGAAC-3' (forward) and 5'-GCCACGATG CCCAGGAA-3' (reverse) for GAPDH. Cav-1 expression was normalized to GAPDH levels and calculated using the $2^{-\Delta \Delta C q}$ method (26). The relative expression of Cav-1 messenger RNA (mRNA) in DRC was indicated as the percentage of mRNA in HCT116 cells.

Western blot analysis. Cells were lysed in cell lysis buffer for western blotting and immunoprecipitation (catalogue no. P0013; Beyotime Institute of Biotechnology, Haimen, China) containing a protease inhibitor cocktail (Roche Applied Science, Madison, WI, USA). Protein samples $(50 \mu \mathrm{g})$ were separated by $12 \%$ SDS-PAGE and transferred to Immobilon-P membranes (EMD Millipore, Billerica, MA, USA). The membrane was blocked with $5 \%$ non-fat dried milk in TBS containing Tween 20 for $1 \mathrm{~h}$ at room temperature, and then incubated overnight at $4{ }^{\circ} \mathrm{C}$ with an anti-Cav-1 mouse monoclonal antibody (mAb) (1:1,000; sc-135860), which was purchased from Santa Cruz Biotechnology, Inc. (Dallas, TX, USA). GAPDH was probed using an anti-GAPDH rabbit $\mathrm{mAb}$ (1:1,000; 5174P; Cell Signaling Technology, Inc., Danvers, MA, USA) overnight at $4^{\circ} \mathrm{C}$ as a loading control. Goat anti-mouse (1:2,000; sc-2005; Santa Cruz Biotechnology, Inc.) and goat anti-rabbit immunoglobulin $\mathrm{G}$ secondary antibodies (1:2,000; sc-2004; Santa Cruz Biotechnology, Inc.) were then incubated for $2 \mathrm{~h}$ at room temperature. An enhanced chemiluminescent-detecting reagent (GE Healthcare Life Sciences, Chalfont, UK) was used for development. The protein blots were quantified by densitometry using QuantityOne software version 4.6.7 (Bio-Rad Laboratories, Inc., Hercules, CA, USA), and the levels were expressed relative to the internal reference GAPDH

siRNA transfection. Cell transfections were conducted using Lipofectamine $^{\mathrm{TM}} 2000$ (Invitrogen; Thermo Fisher Scientific, Inc.) according to the manufacturer's protocol. Cells were additionally grown for $24 \mathrm{~h}$, followed by the addition of $5 \mathrm{mg} / \mathrm{l}$ of 5 -FU for another $72 \mathrm{~h}$. Whole cell lysates were either prepared for immunoblotting, or MTT assay was performed.

Statistical analysis. All the experiments were repeated $\geq 3$ times. Statistical significance was analyzed by Student's t-test using SPSS 11.0 software (SPSS, Inc., Chicago, IL, USA). $\mathrm{P}<0.05$ was considered to indicate a statistically significant difference. Data was presented as the mean \pm standard error of the mean. 
A

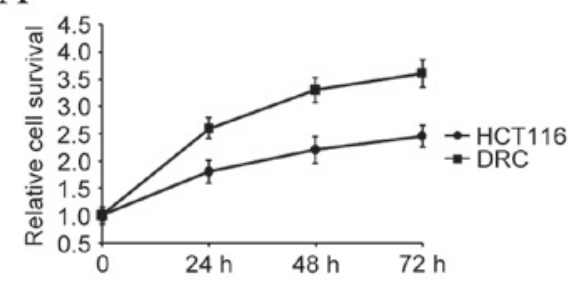

$\mathrm{C}$

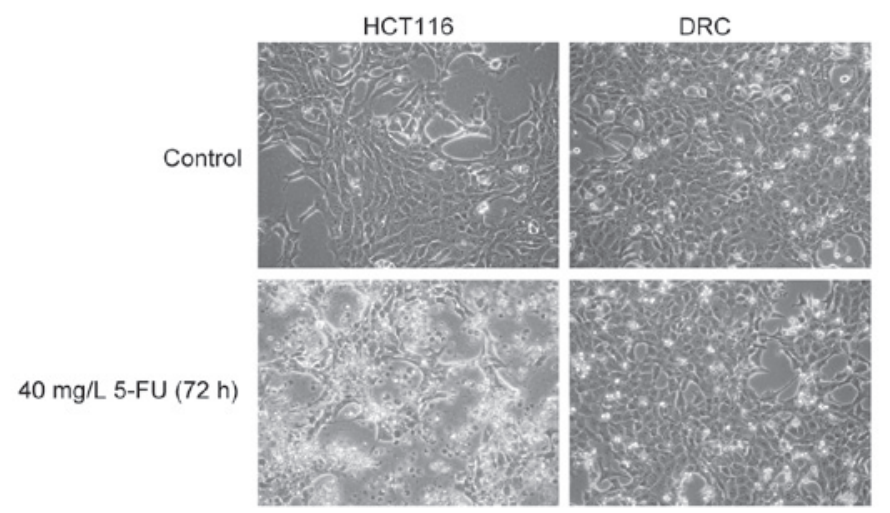

B

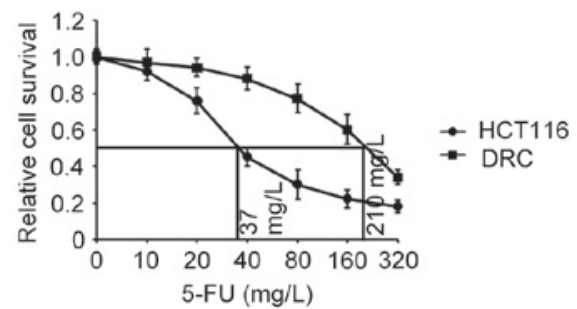

Figure 1. Colorectal cancer cells that were resistant to the 5-FU drug were obtained. (A) Cells were cultured in 96-well plates, and cell growth was detected by MTT assay at the indicated time interval. Growth curve analysis of DRC and HCT116 cells was performed. (B) Cells were incubated in 200 ml of medium for $24 \mathrm{~h}$ and then treated with 5-FU at the indicated concentration for $72 \mathrm{~h}$. Cell survival was assessed by MTT assay. The IC $\mathrm{M}_{50}$ value of DRC was calculated to be $210 \mathrm{mg} / \mathrm{l}$, while that of HCT116 cells was $37 \mathrm{mg} / 1$, at $72 \mathrm{~h}$. (C) DRC and HCT116 cells were exposed to $40 \mathrm{mg} / 1$ of 5-FU for $72 \mathrm{~h}$, and then their morphology was visualized using vertical microscopy at x40 magnification. DRC, drug-resistant cells; 5-FU, fluorouracil.

\section{Results}

Development of drug-resistant colorectal cancer cells to 5-FU. To study the underlying molecular mechanism of drug resistance development in colorectal cancer cells to 5-FU, the 5-FU-resistant colorectal cancer HCT116 cell model was firstly established. Cell survival was evaluated by MTT assay, and growth curves of DRC and HCT116 cells were drawn. DRC grew faster compared withHCT116 cells. As shown in Fig. 1A, the doubling time for the two cell lines was respectively calculated to be 24 and $36 \mathrm{~h}$. Additionally, the concentration required for $50 \%$ inhibition $\left(\mathrm{IC}_{50}\right)$ of 5 -FU was determined by exposing DRC and HCT116 cells to different concentrations of 5-FU for $72 \mathrm{~h}$. The $\mathrm{IC}_{50}$ value of DRC was calculated to be $210 \mathrm{mg} / \mathrm{l}$, while that of HCT116 cells was $37 \mathrm{mg} / \mathrm{l}$, at $72 \mathrm{~h}$ (Fig. 1B). Additionally, cell survival capabilities were compared by treating the two cell lines with $40 \mathrm{mg} / \mathrm{l}$ of 5 -FU for $72 \mathrm{~h}$ and visualizing their morphology. As expected, HCT116 cells were rounded off and displayed membrane blebbing, which is an apoptotic feature (27). However, no obvious changes in DRC morphology were observed (Fig. 1C).

Expression of Cav-1 in DRC and HCT116 cells. To reveal whether the drug resistance-associated protein Cav-1 is involved in the development of resistance to 5-FU in DRC, the expression of Cav-1 was detected. RT-qPCR demonstrated that the mRNA expression level of Cav-1 in DRC was significantly higher than that in HCT116 cells $(\mathrm{P}=0.006)$ (Fig. 2A). In addition, western blot analysis indicated that Cav-1 protein expression was also increased in DRC compared with that in HCT116 cells (Fig. 2B), suggesting that Cav-1 may serves
A

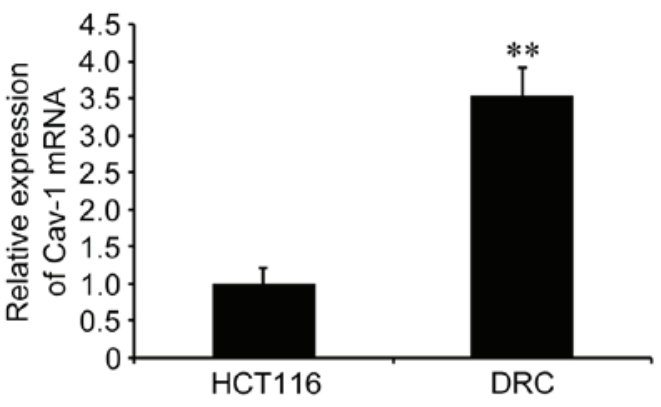

B

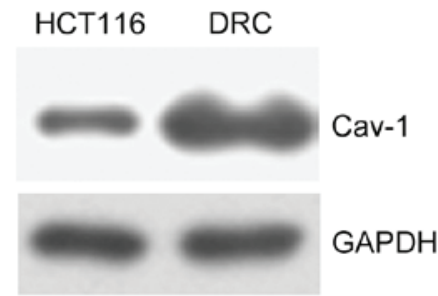

Figure 2. The expression of Cav-1 is increased in DRC. (A) Cells were collected and total RNA was extracted for reverse transcription-quantitative polymerase chain reaction to evaluate the mRNA expression of Cav-1 in DRC and HCT116 cells. ${ }^{* *} \mathrm{P}<0.01$ vs. HCT116 cells. (B) Cells were collected and lysed, and then used to examine the protein level of Cav-1 by western blot analysis using an anti-Cav-1 antibody. GAPDH was detected as an internal standard. DRC, drug-resistant cells; Cav-1, caveolin-1; mRNA, messenger RNA.

an important role in the 5-FU resistance development in colorectal cancer HCT116 cells. 
A

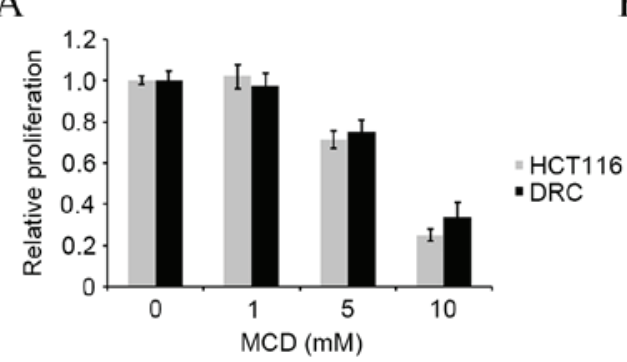

$\mathrm{C}$

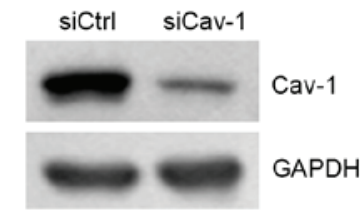

B

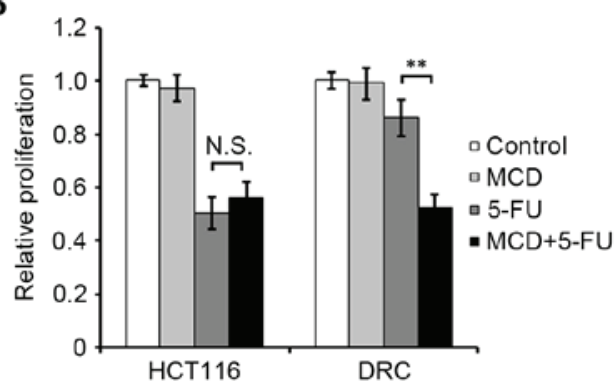

$\mathrm{D}$

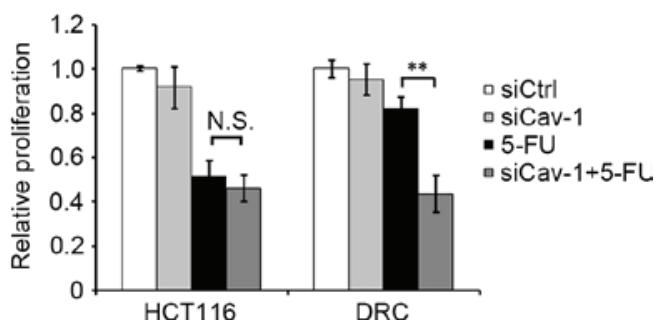

Figure 3. Inhibition of Cav-1 resensitizes DRC to 5-FU. (A) Cells were exposed to medium containing MCD for $4 \mathrm{~h}$. The medium was then removed, and cells were incubated with fresh medium for additional $72 \mathrm{~h}$. Cell survival was examined by MTT assay. (B) Cells were treated with $1 \mathrm{mM} \mathrm{MCD}$ for $4 \mathrm{~h}$, and then incubated in fresh medium with or without $40 \mathrm{mg} / \mathrm{l}$ of 5-FU for $72 \mathrm{~h}$. Subsequently, MTT assay was performed. (C) DRC were treated with control or Cav-1 siRNA. Following 36 h, Cav-1 expression was assessed by western blot analysis. (D) DRC and HCT116 cells were transfected with control or Cav-1 siRNA. After $36 \mathrm{~h}$, fresh medium with or without 5-FU was added for additional 72-h incubation. Cell survival was analyzed using MTT assay. ${ }^{* *} \mathrm{P}<0.01$ vs. 5-FU treatment alone. Cav-1, caveolin-1; DRC, drug-resistant cells; 5-FU, 5-fluorouracil; MCD, methyl $\beta$-cyclodextrin; si/siRNA small interfering RNA; N.S., no significance; Ctrl, control.

Inhibition of Cav-1 resensitizes resistant cells to 5-FU. To investigate the role of Cav-1 in the development of 5-FU resistance, a molecular inhibitor and siRNA for Cav-1 were used to inhibit the function of Cav-1. MCD, a potent inhibitor of Cav-1, suppressed the growth of DRC and HCT116 cells in a dose-dependent manner (Fig. 3A). Additionally, there was no significant inhibitory effect on the survival of $1 \mathrm{mM}$ MCD-treated cells at $72 \mathrm{~h}$. Combination treatment of MCD and 5-FU markedly decreased cell growth of DRC compared that caused by 5 -FU treatment alone, while it did not significantly affect that of HCT116 cells compared with 5-FU treatment alone (Fig. 3B). To verify the function of Cav-1, Cav-1 in cells was silenced by siRNA. Western blotting demonstrated that Cav-1 expression in DRC was inhibited by 5-fold (Fig. 3C). Control siRNA- and Cav-1 siRNA-treated cells were exposed to 5 -FU for $72 \mathrm{~h}$, and cell survival was assessed. MTT assay indicated that cell survival in Cav-1 siRNA-transfected DRC was repressed by 5-FU treatment relative to that in control siRNA-transfected DRC treated with 5-FU alone $(\mathrm{P}=0.008)$ (Fig. 3D). However, under identical experimental conditions, the viability of HCT116 cells was unaffected. These data suggested that downregulation of Cav-1 in DRC enhanced their sensitivity to 5-FU.

\section{Discussion}

Colorectal cancer is one of the most common causes of cancer-associated mortality (28). While non-invasive colorectal cancer may be curable with surgery, for invasive and metastatic cancer, surgery is insufficient for final treatment (29). Chemotherapy is the alternative therapy strategy (30). However, the development of resistance during treatment limits the effectiveness of chemotherapy, as tumor cells may not only obtain resistance to the drug originally used, but may also exhibit cross-resistance to other drugs, which may be triggered possibly by multiple factors with different mechanisms (31-33). Thus, exploring the mechanism of chemoresistance is important to improve cancer treatment.

In the present study, a DRC model was established by varying the concentration of 5-FU treatment that mimicked the phenotype of resistance development in vivo. The survival and growth of DRC and parental HCT116 cells were compared to determine the resistance phenotype. The growth of DRC was increased and was inhibited by 5-FU in a slower manner compared with that of HCT116 cells. It has been reported that elevated expression of Cav-1 is associated with the development of resistance in hepatocellular cancer cells to paclitaxel (27). Additionally, Cav-1 participates in cell survival, tumor progression, metastasis and poor prognosis (19-22). Cav-1 has been found to be correlated with colon cancer growth, metastasis and tumorigenicity $(34,35)$. The present study demonstrated that the expression of Cav-1 was increased in DRC relative to that in HCT116 cells, suggesting that it was involved in drug resistance. In addition, whether cross-resistance of DRC against other therapeutic drugs is generated remains to be explored, which may be valuable for the treatment of cancer.

To verify the hypothesis, a specific inhibitor and siRNA for Cav-1 were used to inhibit the function of Cav-1, which accelerated cell death and resensitized DRC to 5-FU. Taken together, Cav-1 is an important regulator in the development of drug resistance to 5-FU in colorectal cancer HCT116 cells. The present data indicate that chemotherapeutic agents combined with pharmacological inhibitors or siRNAs targeting resistance-associated proteins such as Cav-1 may exhibit increased therapeutic effects for colorectal cancer. 


\section{Acknowledgements}

The present study was supported by the Science and Technology Bureau of Hangzhou City (Hangzhou, China; grant nos. 20130733Q38 and 20130733Q45).

\section{References}

1. Defining Cancer. National Cancer Institute. https://www.cancer gov/about-cancer/understanding/what-is-cancer. Accessed June 10, 2014.

2. Siegel R, Ma J, Zou Z and Jemal A: Cancer statistics, 2014. CA Cancer J Clin 64: 9-29, 2014

3. Wu J, Qiu T, Pan P, Yu D, Ju Z, Qu X, Gao X, Mao C and Wang L: Detection of serum anti-p53 antibodies from patients with colorectal cancer in china using a combination of p53- and phage-ELISA. Asian Pac J Cancer Prev 12: 2921-2924, 2011.

4. Peetla C, Bhave R, Vijayaraghavalu S, Stine A, Kooijman E and Labhasetwar V: Drug resistance in breast cancer cells: Biophysical characterization of and doxorubicin interactions with membrane lipids. Mol Pharm 7: 2334-2348, 2010.

5. Seddon AM, Casey D, Law RV, Gee A, Templer RH and Ces O Drug interactions with lipid membranes. Chem Soc ReV 38 2509-2519, 2009.

6. Righetti SC, Perego P, Carenini N, Corna E, Dal Bo L, Cedrola S La Porta CA and Zunino F: Molecular alterations of cells resistant to platinum drugs: Role of PKCalpha. Biochim Biophys Acta 1763: 93-100, 2006 .

7. Dai Z, Huang Y and Sadée W: Growth factor signaling and resistance to cancer chemotherapy. Curr Top Med Chem 4: $1347-1356,2004$

8. Rossi S (ed): Australian Medicines Handbook (2013 edition). The Australian Medicines Handbook Unit Trust, Adelaide, 2013

9. Tolba MF and Abdel-Rahman SZ: Pterostilbine, an active component of blueberries, sensitizes colon cancer cells to 5-fluorouracil cytotoxicity. Sci Rep 5: 15239, 2015.

10. Ohtsu A: Chemotherapy for metastatic gastric cancer: Past, present, and future. J Gastroenterol 43: 256-264, 2008

11. Williams TM and Lisanti MP: The caveolin proteins. Genome Biol 5: 214, 2004

12. Tang Z, Scherer PE, Okamoto T, Song K, Chu C, Kohtz DS, Nishimoto I, Lodish HF and Lisanti MP: Molecular cloning of caveolin-3, a novel member of the caveolin gene family expressed predominantly in muscle. J Biol Chem 271: 2255-2261, 1996.

13. Scherer PE, Okamoto T, Chun M, Nishimoto I, Lodish HF and Lisanti MP: Identification, sequence, and expression of caveolin-2 defines a caveolin gene family. Proc Natl Acad Sci USA 93: 131-135, 1996.

14. Hill MM, Bastiani M, Luetterforst R, Kirkham M, KirKham A, Nixon SJ, Walser P, Abankwa D, Oorschot VM, Martin S, et al: PTRF-Cavin, a conserved cytoplasmic protein required for caveola formation and function. Cell 132: 113-124, 2008.

15. Hansen CG and Nichols BJ: Exploring the caves: Cavins, caveolins and caveolae. Trends Cell Biol 20: 177-186, 2010.

16. Briand N, Dugail I and Le Lay S: Cavin proteins: New players in the caveolae field. Biochimie 93: 71-77, 2011.

17. Gillet JP and Gottesman MM: Mechanisms of multidrug resistance in cancer. Methods Mol Biol 596: 47-76, 2010.

18. Li S, Couet J and Lisanti MP: Src tyrosine kinases, Galpha subunits, and H-Ras share a common membrane-anchored scaffolding protein, caveolin. Caveolin binding negatively regulates the auto-activation of Src tyrosine kinases. J BiolChem 271: 29182-29013, 1996.
19. Selleri S, Arnaboldi F, Palazzo M, Hussein U, Balsari A and Rumio C: Caveolin-1 is expressed on multipotent cells of hair follicles and might be involved in their resistance to chemotherapy. Br J Dermatol 153: 506-513, 2005.

20. Shajahan AN, Wang A, Decker M, Minshall RD, Liu MC and Clarke R: Caveolin-1 tyrosine phosphorylation enhances paclitaxel-mediated cytotoxicity. J BiolChem 282: 5934-5943, 2007.

21. Tse EY, Ko FC, Tung EK, Chan LK, Lee TK, Ngan ES, Man K, Wong AS, Ng IO and Yam JW: Caveolin-1 overexpression is associated with hepatocellular carcinoma tumourigenesis and metastasis. J Pathol 226: 645-653, 2012.

22. Tang Y, Zeng X, He F, Liao Y, Qian N and Toi M: Caveolin-1 is related to invasion, survival, and poor prognosis in hepatocellular cancer. Med Oncol 29: 977-984, 2012.

23. Selleri S, Arnaboldi F, Palazzo M, Hussein U, Balsari A and Rumio C: Caveolin-1 is expressed on multipotent cells of hair follicles and might be involved in their resistance to chemotherapy. Br J Dermatol 153: 506-513, 2005.

24. Shajahan AN, Wang A, Decker M, Minshall RD, Liu MC and Clarke R: Caveolin-1 tyrosine phosphorylation enhances paclitaxel-mediated cytotoxicity. J BiolChem 282: 5934-5943, 2007.

25. Thomas S, Overdevest JB, Nitz MD, Williams PD, Owens CR, Sanchez-Carbayo M, Frierson HF, Schwartz MA and Theodorescu D: Src and Caveolin-1 reciprocally regulate metastasis via a common downstream signaling pathways in bladder cancer. Cancer Res 71: 832-841, 2011.

26. Livak KJ and Schmittgen TD: Analysis of relative gene expression data using real-time quantitative PCR and the 2(-Delta Delta C(T)) Method. Methods 25: 402-408, 2001

27. Meena AS, Sharma A, Kumari R, Mohammad N, Singh SV and Bhat MK: Inherent and acquired resistance to paclitaxel in hepatocellular carcinoma: Molecular events involved. PLoS One 8: e61524, 2013.

28. American Cancer Society: Cancer Facts \& Figures 2014 American Cancer Society, Atlanta, GA, 2014.

29. Colon Cancer Treatment $\left(\mathrm{PDQ}^{\circledR}\right)-$ Patient Version. National Cancer Institute. https://www.cancer.gov/types/colorectal/ patient/colon-treatment-pdq\#section/all. Accessed June 29, 2014

30. Cunningham D, Atkin W, Lenz HJ, Lynch HT, Minsky B, Nordlinger B and Starling N: Colorectal cancer. Lancet 375: 1030-47, 2010.

31. Szakács G, Paterson JK, Ludwig JA, Booth-Genthe C and Gottesman MM: Targeting multidrug resistance in cancer. Nat Rev Drug Discov 5: 219-234, 2006.

32. Germann UA and Chambers TC: Molecular analysis of the multidrug transporter, P-glycoprotein. Cytotechnology 27: 31-60, 1998.

33. Xu Y, Zhi F, Xu G, Tang X, Lu S, Wu J and Hu Y: Overcoming multidrug-resistance in vitro and in vivo using the novel P-glycoprotein inhibitor 1416. Biosci Rep 32: 559-566, 2012.

34. Nimri L, Barak H, Graeve L and Schwartz B: Restoration of caveolin-1 expression suppresses growth, membrane-type-4 metalloproteinase expression and metastasis-associated activities in colon cancer cells. Mol Carcinog 52: 859-870, 2013.

35. Bender FC, Reymond MA, Bron C and Quest AF: Caveolin-1 levels are down-regulated in human colon tumors, and ectopic expression of caveolin-1 in colon carcinoma cell lines reduces cell tumorigenicity. Cancer Res 60: 5870-5888, 2000. 